\title{
Erratum to: The Centre and the Depth of the Centre for Continuous Maps on Dendrites with Finite Branch
} Points

\author{
Taixiang $\operatorname{Sun}^{1} \cdot$ Hongjian $\mathrm{Xi}^{1}$
}

Published online: 24 July 2017

(C) Springer International Publishing AG 2017

\section{Erratum to: Qual. Theory Dyn. Syst. DOI 10.1007/s12346-016-0204-1}

In the original publication of the article, the acknowledgements at the end of the first page is incorrect. The correct acknowledgements is given below:

Acknowledgements This work was supported by NNSF of China (11261005, 11461003) and NSF of Guangxi (2014GXNSFBA118003, 2016GXNSFBA380235, 2016GXNSFAA380286) and IYMTBA of Guangxi colleges and universities (2017KY0598).

The online version of the original article can be found under doi:10.1007/s12346-016-0204-1.

$凶 \quad$ Taixiang Sun stx1963@163.com

Hongjian Xi x3009h@163.com

1 College of Information and Statistics, Guangxi University of Finance and Economics, Nanning 530003, China 